\title{
Energy assessment of hybrid heat pump systems as a retrofit measure in residential housing stock
}

\author{
David Keogh ${ }^{1}$, Mohammad Saffari ${ }^{1,2, ~ *}$, Mattia de Rosa ${ }^{1,2}$, and Donal P. Finn ${ }^{1,2}$ \\ ${ }^{1}$ School of Mechanical and Materials Engineering, University College Dublin (UCD), Ireland \\ ${ }^{2}$ UCD Energy Institute, University College Dublin (UCD), Ireland
}

\begin{abstract}
Hybrid electric-gas heat pump systems are a possible retrofit option in older residential buildings. Older buildings can be challenging to retrofit and in this context hybrid systems can offer an intermediate route to decarbonisation of building heating energy demand. This is especially the case, where deep retrofit measures coupled with monovalent electric heat pump systems may not be feasible from an economic perspective. The aim of the current paper is to examine the suitability of a hybrid electric-gas heat pump system in comparison to electric heat pump systems as a retrofit measure for Irish housing stock and to benchmark both options against existing fossil fuel baseline systems. A detailed building energy model of a residential dwelling was developed and calibrated to within acceptable ASHRAE standards. An energy assessment was carried out which investigates each retrofit scenario. Key findings include: (i) both the allelectric and hybrid heat pump systems deliver primary energy savings compared to the fossil fuel baseline systems, (ii) hybrid systems attain higher primary energy savings compared to all-electric heat pump, where the hybrid system incorporates flexible delivery temperatures compared to a fixed delivery temperature tor the all-electric heat pump system.
\end{abstract}

\section{Introduction}

Ireland is currently undertaking an ambitious retrofit programme of its building sector. This is likely to continue, as the majority of its buildings are still expected to be operational by 2050 and continued pressure to defossilise and decarbonise the heating sector will remain a priority [1]. In the Irish residential sector, about $6 \%$ of heating supply systems are upgraded or replaced each year, which amounts to approximately 108,000 units. Although, current heating supply technologies are dominated by conventional fossil fuel delivery systems such as natural gas and oil boilers, there is significant potential for deployment of heat pump systems as an alternative to fossil fuel technologies [2]. Defossilisation of the heating sector is a key priority, with measures requiring Ireland to reduce its greenhouse gas (GHG) emissions by $20 \%$ by 2020 and by $40 \%$ by 2030 .

Residential space heating and hot water accounts for $80 \%$ of Irish primary residential energy consumption [3]. Given the significant proportion of heating systems being upgraded each year, there is significant potential for energy savings and GHG abatement in this sector. It is clear that retrofit measures must provide an increase in energy performance as well as a reduction in GHG emissions through increased fabric insulation, infiltration reduction and more efficient heating technologies. The defossilisation of the residential heat sector can be achieved using electrified heat pumps, although this comes with challenges such as increased electrical grid infrastructure and associated operational requirements placed on to the grid. One possible solution is the use of hybrid heat pumps which are an under implemented retrofit option at present. Hybrid heat pumps utilise both electricity and gas as energy supply vectors. Moreover, they can be integrated with existing hydronic heater emitter systems, thereby mitigating the need for emitter upgrade or the need for additional thermal storage measures.

Electric heat pumps are encouraged due to their inclusion in European Directives, but alternatives should also be investigated, as many retrofitted buildings may not be capable of exploiting the full potential of heat pump systems, due to the additional overhead they may cause to the electrical grid. With so many retrofits set to take place over the coming decade, it is possible that one solution may not necessarily optimally work in every instance. For this reason, other low energy heat technologies should be examined so that their merits and demerits can be evaluated in the context of residential retrofit measures.

The aim of the current study is to examine the suitability of a hybrid gas-heat pump heating system in comparison to electric heat pump systems as a retrofit measure for the Irish housing stock and to benchmark these options against typical existing fossil fuel baseline systems.

\section{Methodology}

\subsection{Overview}

The present study is carried out based on an in-situ hybrid heat pump system installed in a residential detached dwelling. An energy model of the integrated system was developed and calibrated to ensure acceptable analysis of the system. Three different retrofitting scenarios are considered and their influence on energy and

* Corresponding author: mohammad.saffari@ucd.ie 
carbon savings is investigated. The building simulation platform, Integrated Environmental Solutions Virtual Environment (IESVE) was used for the analysis [4]. The benchmark system for the technical assessment was the dwelling where no retrofitting had been undertaken and incorporated a natural gas condensing boiler as its heating technology.

\subsection{Experimental case study residential building}

The building is a residential dormer bungalow built in 1999 with a floor area of $160 \mathrm{~m}^{2}$ with an easterly facing aspect. The building is located in Belturbet, Co. Cavan, Ireland. The dwelling was retrofitted from a condensing gas boiler system to a hybrid heat pump system which is the subject of current investigation. A plan of the building is given in Figure 1. Data was collected on site since the installation of the heat pump system in September 2014. The ground floor is a communal living space and the first floor located in the dormer section contains the bedrooms.

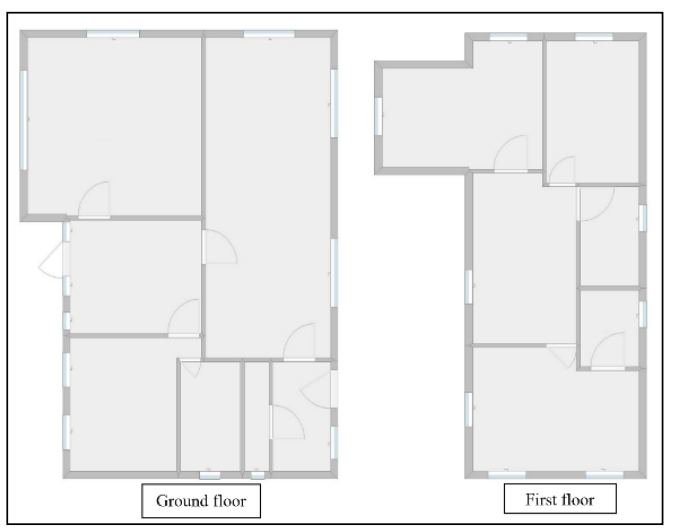

Fig. 1. Experimental dwelling floor plan.

The collected data was logged locally using a meterbus standard communication network and is transferred at a periodic basis using a GPRS network to a central server database, which can be accessed remotely. The data is logged at ten-minute intervals for all data points. The Irish meteorological service, Met Eireann, records weather data at various weather stations and the closest weather station was approximately 10 kilometres from the experimental site. Local weather data was also collected on site, allowing verification of the meteorological data. A root mean square error (RMSE) calculation was performed realising a $\mathrm{RMSE}$ of $1.89^{\circ} \mathrm{C}$ and a mean absolute percentage error (MAPE) of $10.9 \%$ between measured and simulated data.

\subsection{Heat pump}

The system in place is a commercially available air source hybrid heat pump system. It is a split system consisting of an outdoor unit which is the electric air-towater heat pump and an indoor unit containing a condensing natural gas boiler and heat exchanger (see Figure 2). The heat pump has a nominal output of $8 \mathrm{~kW}$ and a $33 \mathrm{~kW}$ nominal output for the gas boiler. The control strategy allows the configuration to work as a hybrid system or on an individual basis. However, the boiler provides the entirety of the domestic hot water. The control strategy of the hybrid heat pump system is based on the outdoor temperature and is regulated by mode (electricity to gas) switching (cut-off) temperature based on external ambient temperature. During periods where the external temperatures are low, and the gas boiler becomes more economical, it provides the complete load, the system works in tandem when producing higher flow temperatures for which the boiler is more proficient, but where the heat pump may also provide a useful contribution. The heat pump provides the full load at higher ambient temperatures which leads to better efficiencies i.e., higher coefficient of performance (COP).

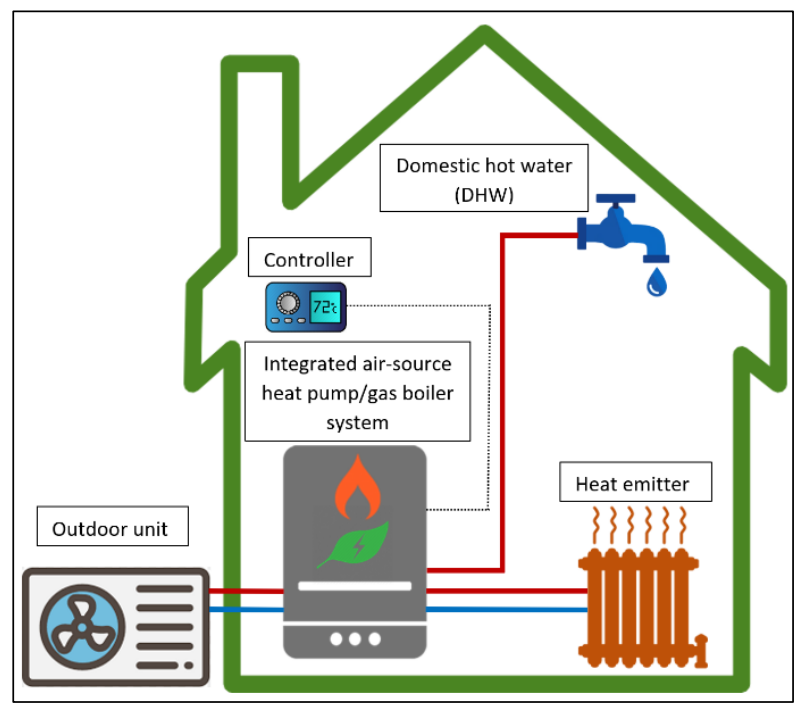

Fig. 2. Hybrid gas-heat pump system schematic.

\subsection{Building prototype numerical modelling}

The building and system model were created using plan drawings of the case study building that was previously described in Section 2.2 and implemented in IESVE. The performance of the gas boiler was based on the CIBSE guide $\mathrm{B}$ and SEAI guidelines with an efficiency of $92 \%$, the performance of the heat pump was modelled based on the collected experimental data $[5,6]$. The cut-off temperature was set to $2^{\circ} \mathrm{C}$, since the performance of heat pump decreases considerably below $2^{\circ} \mathrm{C}$, this is the temperature where the boiler is substituted for the heat pump, as it becomes the more economical heat source. Simulation intervals of two minutes and reporting intervals of ten minutes were selected. A schematic of the building modelled in IESVE is given in Figure 3.

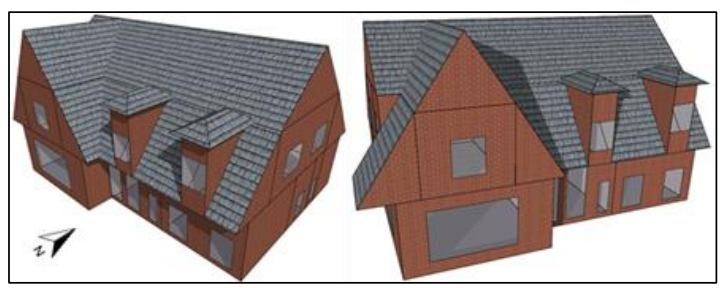

Fig. 3. Modelled bungalow residential building in IESVE. 


\subsubsection{Building construction details}

The construction specifications used in this model are based on the 2002 Building Regulations [7]. The building has ceiling to floor height of 2.5 metres and a total external wall surface area of $139 \mathrm{~m}^{2}$. This external wall includes the wall adjacent to the dormer structure as this is an unfilled cavity. The construction details for the external wall can be found in Table 1.

Table 1. External wall construction Building Reg. Part L 2002.

\begin{tabular}{|c|c|c|c|c|}
\hline \multirow{2}{*}{ Layer } & Thickness & Density & $\begin{array}{c}\text { Heat } \\
\text { capacity }\end{array}$ & Conductivity \\
\hline & (m) & $\left(\mathrm{kg} / \mathrm{m}^{3}\right)$ & $(\mathrm{J} / \mathrm{kg} . \mathrm{K})$ & $(\mathrm{W} / \mathrm{m} \cdot \mathrm{K})$ \\
\hline Rainscreen & 0.003 & 7800 & 450 & 50 \\
\hline Cavity & 0.050 & - & - & - \\
\hline Insulation & 0.065 & 20 & 1030 & 0.025 \\
\hline $\begin{array}{l}\text { Cement } \\
\text { Particle } \\
\text { Board }\end{array}$ & 0.020 & 1100 & 1000 & 0.230 \\
\hline Cavity & 0.050 & - & - & - \\
\hline Plasterboard & 0.015 & 700 & 1000 & 0.210 \\
\hline \multicolumn{5}{|c|}{ Overall U Value: $0.3081 \mathrm{~W} / \mathrm{m}^{2} . \mathrm{K}$} \\
\hline
\end{tabular}

The windows are double-glazing, representative of the 2002 standards (see Table 2). There is a window to wall ratio of 0.22 and a glazed area of $30.5 \mathrm{~m}^{2}$, with majority of the glazing on the ground floor. Windows are present in each room to provide natural light but also contribute heavily to heat loss.

Table 2. External Glazing Detail - Building Reg. Part L 2002.

\begin{tabular}{|l|c|c|}
\hline \multirow{2}{*}{\multicolumn{1}{|c|}{ Layer }} & Thickness & Conductivity \\
\cline { 2 - 3 } & $(\mathrm{m})$ & $(\mathrm{W} / \mathrm{m} . \mathrm{K})$ \\
\hline Inner Pane & 0.006 & 0.150 \\
\hline Cavity (Argon) & 0.008 & - \\
\hline Outer Pane & 0.006 & 0.150 \\
\hline \multicolumn{2}{|c|}{ Overall U Value: $2.15 \mathrm{~W} / \mathrm{m}^{2} . \mathrm{K}$} \\
\hline
\end{tabular}

The exposed floor construction is based on a pre-built construction in IESVE with minor changes made to ensure a U-value similar to that found in the building regulations, it covers a $93 \mathrm{~m}^{2}$ area.

Table 3. Floor Construction - Building Reg Part L 2002.

\begin{tabular}{|l|c|c|c|c|}
\hline \multicolumn{1}{|c|}{ Layer } & Thickness & Density & $\begin{array}{c}\text { Heat } \\
\text { capacity }\end{array}$ & Conductivity \\
\cline { 2 - 5 } & $(\mathrm{m})$ & $\left(\mathrm{kg} / \mathrm{m}^{3}\right)$ & $(\mathrm{J} / \mathrm{Kg} . \mathrm{K})$ & $(\mathrm{W} / \mathrm{m} . \mathrm{K})$ \\
\hline Insulation & 0.075 & 700 & 1000 & 0.022 \\
\hline $\begin{array}{l}\text { Reinforced } \\
\text { Concrete }\end{array}$ & 0.100 & 2300 & 1000 & 2.300 \\
\hline Cavity & 0.050 & - & - & - \\
\hline Flooring & 0.020 & 500 & 1600 & 0.130 \\
\hline \multicolumn{5}{|c|}{ Overall U-Value: $0.25 \mathrm{~W} / \mathrm{m}^{2} . \mathrm{K}$} \\
\hline
\end{tabular}

\subsection{Design conditions}

The heating system is set to maintain an internal temperature of $20^{\circ} \mathrm{C}$ with a $1^{\circ} \mathrm{C}$ dead band throughout the year which is derived from the average internal temperature sensor during occupied hours and is in line with the industry standards to maintain comfort conditions in dwellings [8]. The infiltration is set at 0.5 $\mathrm{ach}^{-1}$ for the house and $1 \mathrm{ach}^{-1}$ for the void spaces [8]. The building schedules are maintained constant over the year, excluding July and August, when the space heating system is not operating. The building is assumed to be occupied at all hours through the year and the heating system is set to keep the building at desired comfort temperature between the hours of $7 \mathrm{am}$ and $10 \mathrm{pm}$. Additionally, the price of oil, natural gas, and electricity are taken as $0.080 € / \mathrm{kWh}, 0.065 € / \mathrm{kWh}$, and $0.20 € / \mathrm{kWh}$, respectively, according to Irish domestic fuel prices [9]. These prices do not include consumption taxes nor utility standing charges.

\subsection{Climate conditions and location}

The simulation model uses the same climatic condition as the experimental model, Belturbet, Co. Cavan to achieve results as accurate as possible. The model weather data made available by ASHRAE [10] was located in Clones, Co. Monaghan, Ireland which is approximately 16 kilometres from Belturbet and provides data that is close to that expected at the site.

\subsection{Verification of energy model}

As experimental data was available calibration was possible. Space heating energy consumption was compared for an initial three month period (Dec 2014 to Feb 2015) when no retrofit measures were implemented (see Fig 4). Over the three month period, the various error metrics were as follows: $\mathrm{MAPE}=3.5 \%, \mathrm{RMSE}=196$ $\mathrm{kWh}$ and CVRMSE $=6.5 \%$, all of which are within the acceptable guidelines dictated by ASHRAE [11].

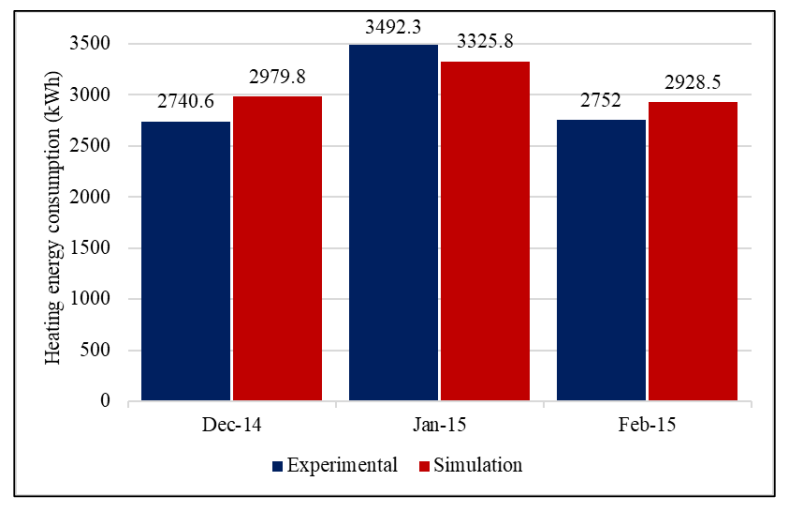

Fig. 4. Comparison of simulation model with experimental data. 


\subsection{Energy retrofitting scenarios}

Four different scenarios were considered to analyse the energy consumption and carbon emissions savings of different heating systems implemented in the residential building model (see Table 4.)

Scenario (a) is the base case with an oil-fired boiler (OB). It is based on the field test residential building. Its heating system uses an oil-fired boiler with a design flow temperature of $70^{\circ} \mathrm{C}$; and the heating distribution system uses traditional steel radiators (STL-RAD) throughout the dwelling.

Scenario (b) is the base case with a natural gas condensing boiler (CGB). Its heating system incorporates a natural gas boiler with a design flow temperature of $60^{\circ} \mathrm{C}$, the heating distribution system uses STL-RAD throughout the dwelling.

Scenario (c) is the base case building with the hybrid heat pump (HHP). It integrates a hybrid heat pump with a design flow temperature between $35^{\circ} \mathrm{C}$ and $55^{\circ} \mathrm{C}$, the heating distribution system uses aluminium radiators (ALU-RAD) throughout the dwelling, which operate more efficiently at lower temperatures than more conventional steel radiators.

Scenario (d) is the base case building with the electric heat pump. This heating system integrates an electric airto-water heat pump (EHP) with a design flow temperature of $55^{\circ} \mathrm{C}$. Efficient ALU-RAD were used for heating distribution throughout the dwelling.

It should be considered that for all four scenarios, no building envelope retrofit measures were implemented. Furthermore, in Scenarios (c) and (d), the heating systems were designed to be capable of delivering a maximum flow temperature of $55^{\circ} \mathrm{C}$.

Table 4. Retrofitting scenarios.

\begin{tabular}{|c|c|c|c|}
\hline Scenario & Distribution & Fuel & $\begin{array}{c}\text { Flow Temp. } \\
\left({ }^{\mathbf{}} \mathbf{C}\right)\end{array}$ \\
\hline (a) & STL-RAD & Oil & 70 \\
\hline (b) & STL-RAD & Nat. Gas & 60 \\
\hline (c) & ALU-RAD & Elec./Nat. Gas & $35-55$ \\
\hline (d) & ALU-RAD & Elec. & 55 \\
\hline
\end{tabular}

\subsection{Primary energy use analysis}

The primary energy factor (PEF) describes the efficiency of converting energy from primary sources [12]. PEF is defined as the ratio of primary energy to secondary energy for a specific energy vector. PEF is included in analyses to provide a way of interpreting the primary energy efficiency of the heat source that is being investigated. In the present study, as different heating systems are investigated, the calculation of PEF differs from system to system. PEFs for heat production in case of heating systems with oil, and natural gas boilers were calculated using Equation (1) [13]. Data for the source PEF of natural gas and oil was derived from Ecoinvent 3.1 [14] as having a PEF equal to 1.15 for both fuels.

$P E F_{h p}=P E F_{h s} / \eta_{h s}$ where $\mathrm{PEF}_{\mathrm{hp}}$ is the primary energy factor for heat production, $\mathrm{PEF}_{\mathrm{hs}}$ is the primary energy factor of heat source, and $\eta_{h s}$ is the efficiency of the heating system. In this study, efficiencies of 0.80 and 0.90 were used for oil and gas boilers, respectively.

The PEF for heat production in case of air-source heat pump heating system was calculated using Equation (2) [13]:

$$
P E F_{h p}=P E F_{e l} / S P F
$$

where $\mathrm{PEF}_{\mathrm{el}}$ is the primary energy factor of electricity, and SPF is the seasonal performance factor of the heat pump. The PEF for the Irish electrical grid is $2.08[10,11]$. The SPF of the heat pump is calculated using Equation (3) [13]:

$$
S P F=Q_{h p} / W_{e l}
$$

where $\mathrm{Q}_{\mathrm{hp}}$ is the the annual produced heat, and $W_{e l}$ is the annual electricity consumption of the heat pump system.

For the hybrid heat pump system, the COP of a conventional electric heat pump cannot be used, but a separate formula that incorporates both the efficiency of the boiler and the COP of the heat pump should be utilised. To define the hybrid air-source heat pump/gas boiler system performance factor, the methodology of Stafford [15] was used, which can be calculated using Equation (4):

$$
S P F_{h h p}=W_{u h} / Q_{f u e l}
$$

where $\mathrm{SPF}_{\text {hhp }}$ is the hybrid system performance factor, $\mathrm{W}_{\mathrm{uh}}$ is the sum of the net useful heating effect, and $\mathrm{Q}_{\text {fuel }}$ is the total fuel energy input into both systems.

The PEF of the hybrid heating system can be calculated using Equation (5):

$$
\mathrm{PEF}_{\mathrm{hhp}}=\left(\left(P E F_{h s} / \eta_{h s}\right) \times R_{\text {gas }}\right)+\left(\left(P E F_{\text {el }} / S P F\right) \times R_{\text {el }}\right)
$$

where $R_{\text {gas }}$ is the ratio of space heating provided by gas boiler, $R_{e l}$ is the ratio of space heating provided by heat pump, and SPF is the seasonal performance factor of the heat pump. With knowledge of the PEFs of all heating systems, the primary energy savings (PES) can be calculated using Equation (6). In the present study, the reference PEF of renewable electricity generation is set equal to 1.0, which was considered to calculate PES [16].

$$
P E S=(1-P E F) \times 100 \%
$$

\subsection{Carbon dioxide $\left(\mathrm{CO}_{2}\right)$ emissions}

The carbon intensity for each scenario is quantified using the metric ( $\mathrm{tCO}_{2} /$ year), where the emission factors for each fuel vector uses the appropriate national conversion factors. On this basis, emission factors of 
$0.2639 \mathrm{~kg} / \mathrm{kWh}$ for oil, $0.2047 \mathrm{~kg} / \mathrm{kWh}$ for natural gas, and $0.4366 \mathrm{~kg} / \mathrm{kWh}$ for electricity were considered $[16,17]$. The annual carbon intensity can be calculated using Equation (7).

$$
\varepsilon=\mathrm{Q} \times E F / 1000
$$

where $\varepsilon$ is the carbon intensity in tonnes $\mathrm{CO}_{2}$ per year, $\mathrm{Q}$ is the energy use in $\mathrm{kWh}$, and EF is the emissions factor for each fuel vector. It is noted that in the case of the hybrid heat pump system (Scenario (c)), the emissions of both the natural gas and the electricity fuel vectors are summed.

\subsection{Systems running costs}

Irish domestic fuel prices [9] for oil, natural gas, and electricity were considered to calculate the annual running costs. Consumption taxes and utility standing charges have been omitted. The annual running costs of the scenarios are calculated using Equation (8).

$$
R C=\mathrm{Q} \times C_{e}
$$

where $R C$ is the annual running cost of the system in euros, and $C_{e}$ is the cost of energy per kWh in euros. For Scenario (c), the annual running cost of electricity and natural gas are summed.

\section{Results}

\subsection{Primary energy use}

Figure 5 compares the primary energy consumption for the four scenarios. It shows that the oil and gas-based heating systems have higher primary energy use compared to the two heat pump systems. In case of Scenarios (c) and (d), the primary energy consumption is not significantly different; this is due to the hybrid system having the ability to operate with different design flow temperatures based on the external temperatures, whereas the all-electric HP system operates with a single water delivery temperature. There is a $17 \%$ difference in the primary energy consumption between scenario (c) and (d), which is due to a slightly higher operational efficiency associated with the hybrid heat pump system.

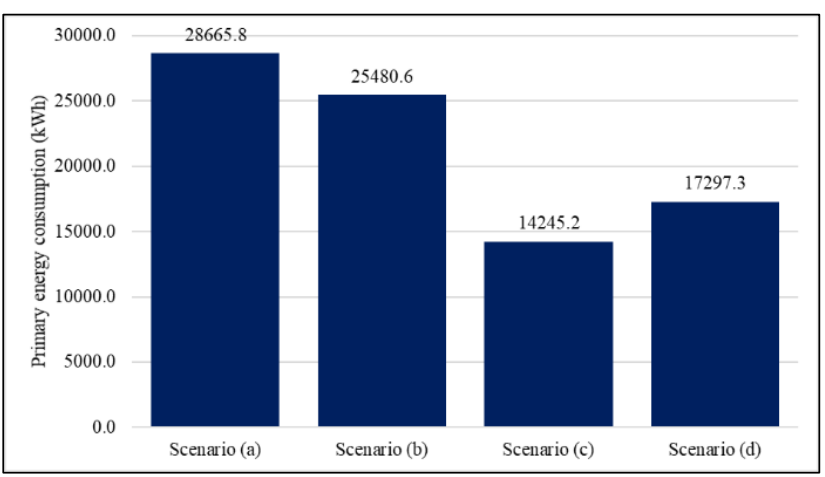

Fig. 5. Primary energy consumption: Scenarios (a), (b), (c) \& (d).

\subsection{Primary energy savings}

The primary energy savings (PES) for each scenario are presented in Figure 6. It can be seen that the hybrid heat pump (Scenario (c)) and the all-electric heat pump (Scenario (d)) exhibit PES benefits, whereas the OB and CGB do not achieve any primary energy savings. For Scenario (c), the ratio of gas to electricity $(3: 5)$ has a significant impact on PES due to the low boiler efficiencies at certain conditions, which results in an increased Primary Energy Factor (PEF). This is because the overall PEF is strongly dependant on heat pump performance, as the PEF of electricity is considerably higher than that of gas. Considering the PES associated with the hybrid heat pump (Scenario (c)), it is the proportion of utilised fuels that play the most significant role in determining the PES in conjunction with the heat pump performance. In the present study, the annual consumption of gas and electricity was $37.5 \%$ and $62.5 \%$, respectively. For the case of the all-electric heat pump system, if the heat pump COP is less than 2.08 , a negative PES would be realised. In addition, the results show that all systems incorporating a heat pump achieve a positive PES.

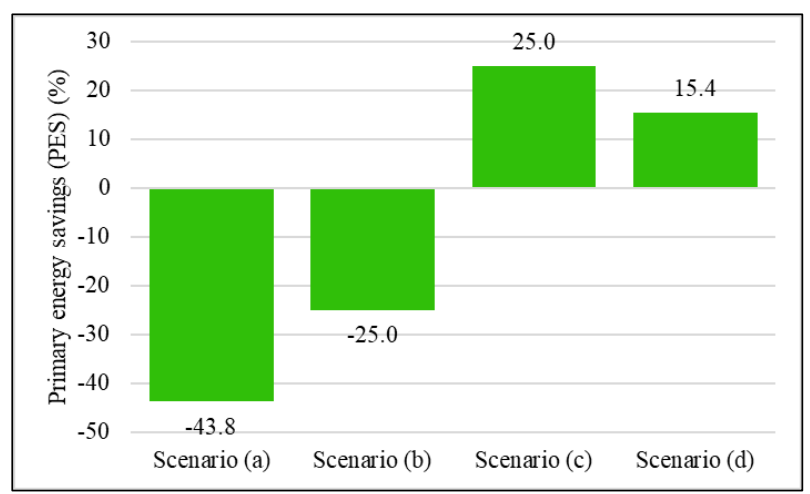

Fig. 6. Primary energy saving: Scenarios (a), (b), (c) \& (d).

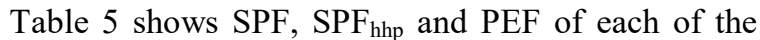
scenarios. It can be seen that the annual SPF of all-electric heat pump is slightly higher than the hybrid heat pump. Additionally, systems based on fossil fuels (Scenarios (a) and (b)) have higher PEF compared to Scenarios (c) and (d) with electric heat pump.

Table 5. Performance metrics: Scenarios (a), (b), (c) \& (d).

\begin{tabular}{|c|c|c|c|}
\hline Scenario & SPF & SPF $_{\text {hhp }}$ & PEF \\
\hline (a) & -- & -- & 1.44 \\
\hline (b) & -- & -- & 1.28 \\
\hline (c) & -- & 2.36 & 0.75 \\
\hline (d) & 2.44 & -- & 0.85 \\
\hline
\end{tabular}

\subsection{Carbon dioxide emissions savings}

Figure 7 illustrates the effect of different systems on carbon emissions for the test case building. As can be seen 
in Table 5, although Scenario (d) has a higher SPF in comparison to Scenario (c), it also has a higher carbon intensity, achieving only a $11.5 \%$ reduction in comparison to the condensing gas boiler system (Scenario (b)). Scenario (c) consisting of a hybrid heat pump achieves almost three times the reduction with a $31.5 \%$ reduction in carbon emissions. This can be justified because when the outdoor air temperature is low, the electric HP system runs with a reduced COP, which results in increased electricity consumption and carbon emissions. However, in case of the hybrid heat pump system, the period during which the electric heat pump runs with a low COP is limited, because when the outdoor air temperature is low, the control system switches to gas boiler mode.

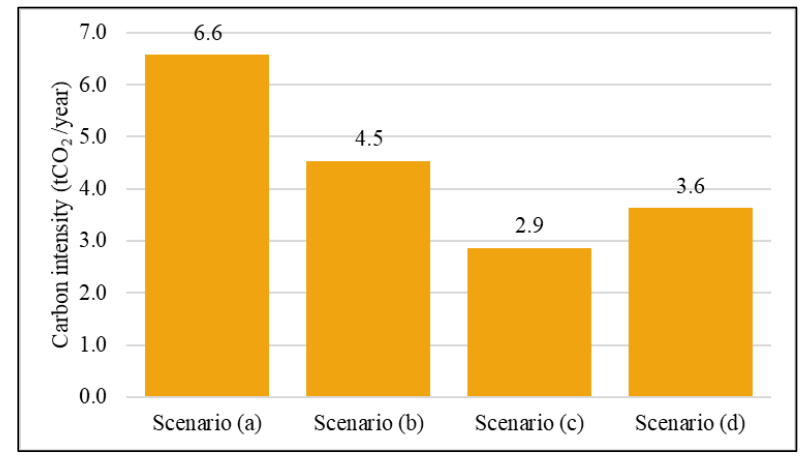

Fig. 7. Annual $\mathrm{CO}_{2}$ emissions: Scenarios (a), (b), (c) \& (d).

\subsection{Final energy cost}

Figure 8 summarises the annual operational costs. It can be seen that higher delivery temperatures associated with the all-electric heat pump (Scenario (d)) results in additional annual running costs (by 15) compared to Scenarios (b) and (c). However, the hybrid heating system (Scenario (c)) has a reduced running cost, by $39 \%$ and $15 \%$ in comparison to Scenarios (a) and (b), respectively. The all-electric heat pump operating at higher flow temperatures does not achieve lower running costs due to the significantly more expensive cost of electricity in comparison to natural gas and oil. Other researchers achieved similar results with hybrid systems [18].

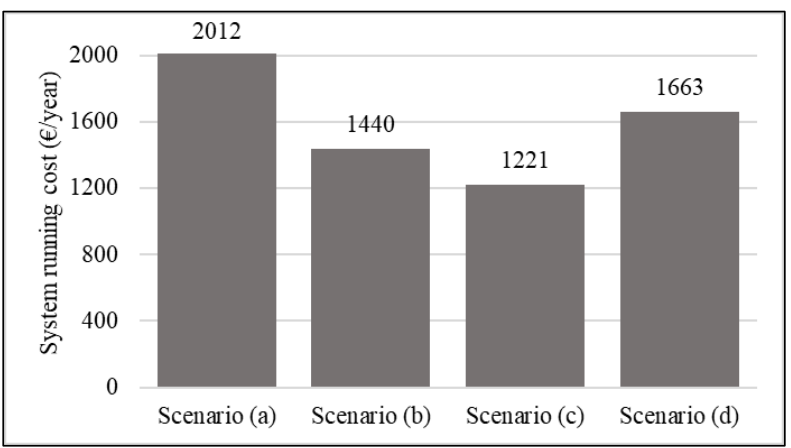

Fig. 8. Annual running costs of different scenarios.

\section{Conclusions}

The objective of the present study was to determine the feasibility of the integration of hybrid heat pumps as a measure for retrofitting residential building stock in Ireland. A detailed energy model of the residential building was developed using the IESVE software package, which was calibrated to within ASHRAE standards.

Four technology retrofit scenarios were examined, which included an oil boiler system, a gas boiler system, a hybrid heat pump system and an all-electric system. Water delivery temperature was found to have a high impact on the performance of the two heat pump systems, and as expected especially on the hybrid electric system The all-electric heat pump system with water delivery temperature of $55^{\circ} \mathrm{C}$ has higher annual running costs $(1663 €)$ when compared to hybrid heat pump system $(1221 €)$, with a water delivery temperature of $35^{\circ} \mathrm{C}-55^{\circ} \mathrm{C}$. It should be noted that the all-electric heat pump has a higher water flow delivery temperature $\left(55^{\circ} \mathrm{C}\right)$, which may mitigate against its performance.

Both the all-electric and hybrid heat pump achieve primary energy savings, with the hybrid system attaining a higher level of PES (9.6\%) and final energy savings (442 $€ /$ year) compared to the all-electric heat pump. Additionally, the hybrid heat pump system has the lowest annual carbon intensity (2.9 tCO2) compared to the other systems.

In future studies, the use of underfloor heating with lower water flow delivery temperature together with building envelope retrofitting will be investigated to improve the performance of all-electric heat pump and hybrid heat pump systems.

\section{References}

This publication has emanated from research conducted with the financial support of Science Foundation Ireland (SFI) under the SFI Strategic Partnership Programme Grant Number SFI/15/SPP/E3125.

1. International Energy Agency (IEA), Transition to Sustainable Buildings, Strategies and Opportunities to 2050, (2013).

2. Sustainable Energy Authority of Ireland (SEAI), Energy in Ireland 2016, (2016). https://www.seai.ie/resources/publications/Energ y-in-Ireland-1990-2016-Full-report.pdf (accessed Nov, 2018).

3. Sustainable Energy Authority of Ireland (SEAI), Energy In The Residential Sector 2018 Report, (2018).

https://www.seai.ie/resources/publications/Energ $\mathrm{y}$-in-the-Residential-Sector-2018-Final.pdf (accessed Sept, 2018).

4. Integrated Environmental Solutions, (2018). https://www.iesve.com/ (accessed Nov, 2018). 
5. CIBSE, Applications and activities: HVAC strategies for common building types, (2016).

6. Sustainable Energy Authority Ireland (SEAI), HARP Database, (2018) https://www.seai.ie/energy-in-business/berassessor-support/harp-database/ (accessed Dec, 2018).

7. Ireland Department of the Environment and Local Government, Building Regulations 2002 Technical Guidance Document L Conservation of Fuel and Energy DWELLINGS, Dublin, (2002).

8. CIBSE, Environmental design: CIBSE guide A, (2015).

https://www.cibse.org/knowledge/knowledgeitems/detail?id=a0q20000008I79JAAS (accessed Nov, 2018).

9. Sustainable Energy Authority of Ireland (SEAI), Domestic Fuels Comparison of Energy Costs, (2018).

https://www.seai.ie/resources/publications/Dome stic-Fuel-Cost-Comparison.pdf (accessed Dec, 2018)

10. ASHRAE, ASHRAE International Weather for Energy Calculations 2.0, (2018). http://ashrae.whiteboxtechnologies.com/ (accessed Dec, 2018).

11. ANSI/ASHRAE, Guideline 14-2015 Measurement of Energy and Demand Savings, (2015).

12. P. Poredoš, T. Čož, A. Kitanovski, A. Poredoš, Thermo-economic and primary-energy-factor assessment based on the field test of an air-towater heat pump, Int. J. Refrig. 76 (2017) 19-28. doi:10.1016/J.IJREFRIG.2017.02.003.

13. B. Vidrih, A. Kitanovski, A. Poredo, Eligibility of a Heat Pump Based on the Primary Energy Factor, (2017) 1-13.

14. ecoinvent $3.1 \quad-\quad$ ecoinvent, (2018). https:/www.ecoinvent.org/database/olderversions/ecoinvent-31/ecoinvent-31.html (accessed Nov, 2018).

15. A. Stafford, An exploration of load-shifting potential in real in-situ heat-pump/ gas-boiler hybrid systems, (2017). doi:10.1177/0143624416688727.

16. A. Esser, F. Sensfuss, Review of the default primary energy factor (PEF) reflecting the estimated average EU generation efficiency referred to in Annex IV of Directive 2012/27/EU and possible extension of the approach to other energy carriers, (2016). www.isi.fraunhofer.de (accessed Nov, 2018).

17. Sustainable Energy Authority of Ireland (SEAI),
Conversion Factors, SEAI Statistics, (2018). https://www.seai.ie/resources/seaistatistics/conversion-factors/ (accessed Nov, 2018).

18. S. Heinen, D. Burke, M. O'Malley, Electricity, gas, heat integration via residential hybrid heating technologies - An investment model assessment, Energy. 109 (2016) 906-919. doi:10.1016/j.energy.2016.04.126. 